\title{
Foro I I: Nuevos roles en la educación superior de arquitectura
}

Forum I: New roles in higher
education of architecture

$<$ Resumen>

Distinguidos arquitectos de nuestra casa de estudios, son invitados por "De Arquitectura" a evaluar el traspaso disciplinar desde la docencia a la profesión, y viceversa.

$<$ Abstract $>$

Distingui shed architects of our school have been invited by De Arquitectura to debate about higher education and the formation of new prof essi onal s.

Lugar: Confitería Torres, Cava del Bicentenario (5 de mayo de 2006).

Pl ace: Confitería Torres, Cava del Bi centenario (May $5^{\text {th }}$ 2006).

<Moderador>

Arq. Leopoldo Prat V. / LP:

Socio de IglesistPrat Arquitectos. Profesor de pregrado y título en la Universidad de Chile.

$<$ Invitados>

Arq. Ernesto Calderón A. /EC:

Magíster en Urbanismo, Universidad de Chile. Profesor de pre y posgrado en la Universidad de Chile.

Arq. Patricio Morelli U. /PM:

Socio de "José Gabriel Alemparte - Patricio Morelli \& Asociados Arquitectos". Past President de la Asociación de Oficinas de Arquitectos. Profesor de pregrado y título en la Universidad de Chile.

Arq. María Eugenia Pallarés T. / MP:

Master en Dirección de Empresas Constructoras e Inmobiliarias MDI - Universidad Politécnica de Madrid. Directora Escuela de Posgrado. Profesora de pre y posgrado en la Universidad de Chile.

Arq. Verónica Serrano M. IVS:

Directora Nacional de Arquitectura Ministerio de Obras Públicas.

$<$ Palabras clave>

EDUCACIÓN DE ARQUITECTURA / UNIVERSIDAD Y SOCIEDAD / EDUCACIÓN ESPECIALISTA VERSUS GENERALISTA / CAMPO LABORAL ARQUITECTURA / FORMACIÓN DE ARQUITECTOS

$<$ Key words >

EDUCATI ON I N ARCHI TECTURE / UNI VERSI TY AND SOCI ETY / SPECI ALI ZATI ON VS. GENERAL EDUCATI ON I ARCHI TECTURE LABOR FIELD / FORMATI ON OF ARCHI TECTS

\section{Introducción}

/ LP: La idea es centrarnos de alguna forma en el tema que plantea este número: Grandes Operadores - Pequeños Negocios

El arquitecto requiere hoy de iniciativas y destrezas para subsistir competitivamente y para desempeñarse integralmente. ¿Cómo estamos abordando estos desafíos desde la docencia para formar y preparar al futuro profesional? Es una de las preguntas que interesa abordar. A modo de anécdota yo podría contar que cuando salí de la universidad y me enfrenté al medio, nuestra formación estaba orientada casi exclusivamente a ser parte del estamento estatal. La Universidad de Chile nos preparaba para funcionar en lo que era el Estado, ya que en ese momento también su rol era muy distinto al que hoy día se plantea el arquitecto; de hecho los estamentos estatales tenían mucha ejecución en términos de proyectos, no eran como hoy día, más bien normativos. Para el ejercicio profesional, la enseñanza de la escuela estaba muy orientada a esa formación. Creo que una de las virtudes de la universidad es poder abrir a la persona la posibilidad de 


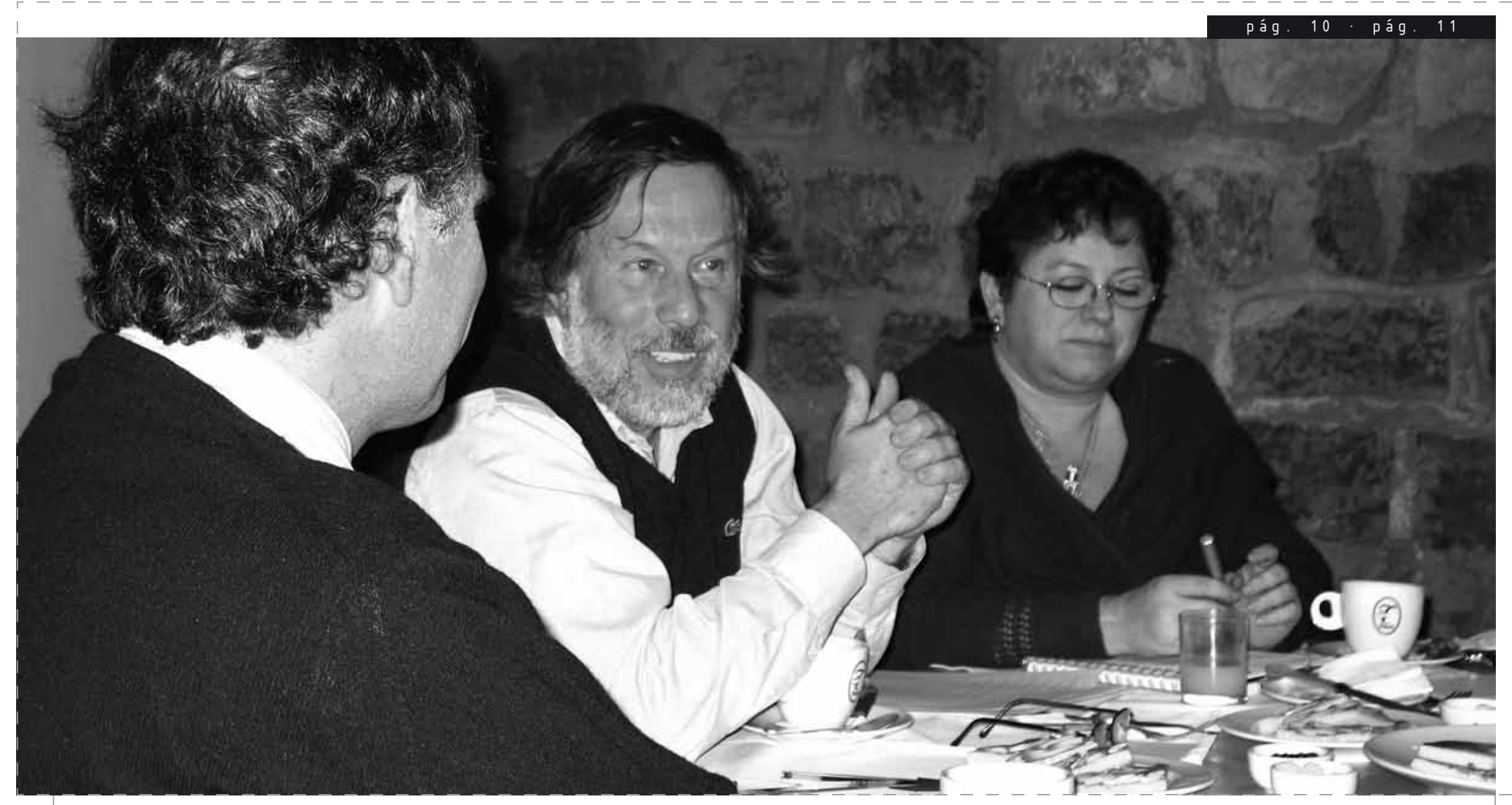

saber responder a los cambios, de hecho, hoy día es muy distinta la situación que se plantea al egresar, y ese es uno de los puntos que me gustaría que ustedes pudieran abordar.

\section{Estado, Docencia y Universidad}

/ MP: Voy a tomar las últimas palabras que tú dijiste (...), si uno mira desde el punto de vista de la docencia, creo que cualquier plan de estudio, cualquier formación profesional, debe caracterizarse por la flexibilidad.

Creo que nosotros, la Universidad, tenemos que estar recogiendo lo que está pasando, y en ese sentido no sólo con la mirada a lo inmediato, sino con la mirada a lo que viene de otros ambientes más desarrollados; o sea, si uno piensa en la formación de los arquitectos en la época de Leopoldo ${ }^{1}$, era orientada a una gestión pública. En la época que yo estudié era un poco más intermedia, o sea, había una gestión pública importante, pero también había mucho énfasis en la gestión privada. Hoy día es casi absolutamente privada. Pero eso no implica que el ámbito de la gestión pública se haya cerrado; creo que se ha transformado, que se ve de otra manera la gestión pública, pero creo que hay una participación tremendamente importante del Estado, interpretada en cada una de sus instancias, que abarca desde los ministerios a los municipios, y creo que el tema es saber poner en valor la gestión que realizan las personas que están en esas instituciones.

Refiriéndose al aspecto normativo, por Dios que es importante el aspecto normativo. Si uno analiza culturas más desarrolladas -estoy pensando en el director de obras de la municipalidad de París- su rol es tremendamente importante, la función que el cumple es una función muy valorada, muy respetada, y a la que se accede de una manera muy especial, no se llega desde cualquier punto, se llega después de una tremenda carrera porque los proyectos que se están evaluando, las cosas que se están organizando, las normativas que se están gestando, tienen que ver con el concepto de ciudad, por lo tanto, hay una valorización, una valoración más bien de la gestión que se cumple en cualquiera de estos ambientes.

Entonces creo que el tema no es si hemos cambiado de un modelo a otro, si tenemos que cambiar de un plan de estudio a otro, yo creo que lo que hay que hacer primero es ser flexible. En el sentido de que las oportunidades están siempre ahí. Ahora, la fortaleza de un plan de estudio y de la formación de cualquier profesión tiene que estar en la detección de las oportunidades, y las oportunidades se tienen que ver muy anticipadamente, porque ese es su rol, ir más adelante de lo que el mercado te está pidiendo, ir detectando cuáles son las oportunidades que se están abriendo; y creo que en ese sentido las dinámicas no acompañan, o sea, las dinámicas universitarias no están muy relacionadas con las dinámicas de los medios. El medio es mucho más activo, creo que es mucho más veloz en sus cambios, que aporta cuestiones, que abre una cantidad de puertas que la universidad debe estar lo suficientemente alerta para captar, eso sin dejar de lado aquellas cuestiones que son intransables, que no se modifican, que son como el piso, como la base permanente.

/ PM: Respecto a este tema que tiene muchas aristas, lo primero que yo quiero hacer es una declaración de principios: yo soy optimista. Si bien es cierto, hace veinticinco años, cuando salí de la escuela, la visión que uno tenía de la arquitectura era una visión romántica. Uno sentía, que la sociedad valoraba mucho la profesión y por lo tanto teníamos un futuro muy promisorio. Yo creo que eso hoy día todavía sigue siendo así en alguna medida con algunos énfasis distintos.

En 1981, se promulgó el Decreto con Fuerza de Ley N¹, que reformó la educación en Chile permitiendo, entre otras cosas, la creación de universidades privadas. Antes de esto, habían muy pocas escuelas de arquitectura. 


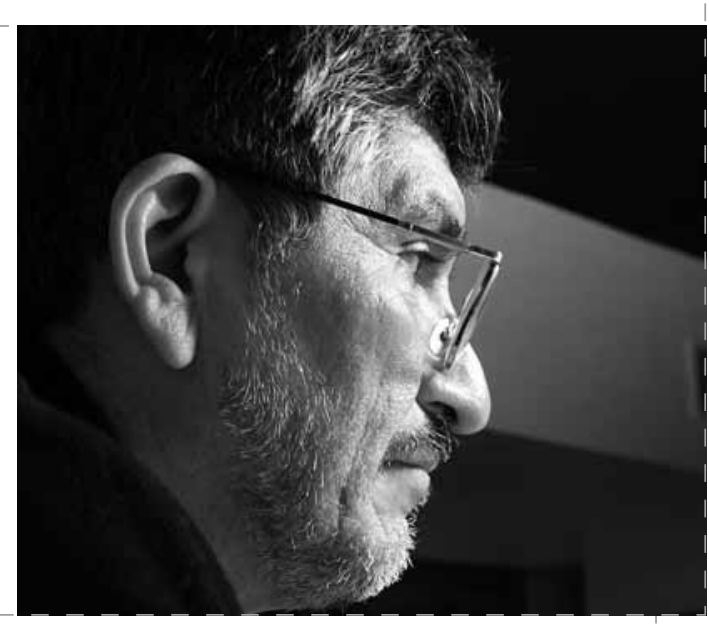

Creo que respecto al tema del Estado, por ejemplo, hace 25 ó 30 años el Estado era un gran generador de trabajo para los arquitectos. Creo que en la medida que el país siga desarrollándose, ello implicará un Estado que va a volver a hacer obras de otro tipo, con otros sistemas de gestión. Las "concesiones" hoy día son una realidad, pero son gestión del Estado también ${ }^{2}$, entonces yo creo que en la medida que nos desarrollemos económicamente, vamos a tener un Estado cada vez más rico, que va a invertir más, por la vía que sea, por las concesiones o directamente. Eso va a implicar que nosotros evidentemente tendremos que estar más preparados para más complejidades. El arquitecto efectivamente -como tú dices- tiene que ser muy flexible, muy versátil, muy abierto a enfrentar desafíos.

Si bien soy optimista, creo que la sociedad regula todas estas cosas en forma natural. Por ejemplo el tema de las universidades privadas respecto a las universidades tradicionales. Nosotros (los contertulios) fuimos todos formados en universidades tradicionales, pero yo creo que el rol que están teniendo las universidades privadas -y que van a tener cada vez más en el futuro- está relacionado justamente con esa capacidad más cercana de adaptarse rápidamente a los cambios sociales y a los cambios económicos del mercado. Por lo tanto nosotros, las universidades tradicionales, como estamos compitiendo con ellas, inevitablemente tenemos que incorporarnos a esa dinámica, y estamos en ese proceso. Entonces yo diría que efectivamente, para redondear la idea, estamos en una sociedad compleja y nuestra profesión hoy día tiene tópicos, mucho más complejos que antes. Los arquitectos hace veinticinco o treinta años teníamos la vivienda o el equipamiento como grandes temas.
Hoy día el tema del equipamiento es de una bastedad que no tiene límites... cada cinco años se inventa un nuevo servicio, un nuevo sistema de promover servicios. Está el tema cultural, el de la educación, el de la justicia, los temas son infinitos. Finalmente creo que la sociedad se encarga de regular estos procesos en que estamos inmersos. Yo soy optimista, ese es mi planteamiento.

/ EC: A ver... cuando me invitaron a participar en este foro me asusté un poco, porque considero que es difícil tomar cierta distancia para poder tener claridad sobre lo que nos está pasando en nuestra contemporaneidad, más aún cuando todos aceptamos que vivimos en una realidad extremadamente compleja. Creo que el primer problema que tenemos es que no hacemos nuestra esa complejidad, o sea la aceptamos, pero no la internalizamos ni siquiera desde el ámbito de la academia, instancia que debería ser la primera en asumir esta realidad compleja. Creo que todavía estamos en esa fase de desorientación, de no saber cómo reflejar, cómo asumir desde cada uno de nuestros papeles esa complejidad.

Hay algunos ámbitos profesionales que lo han hecho un tanto mejor que nosotros. Hay algunas ciencias que ya asumen esa complejidad y les ha obligado a reformular sus soportes: epistemológicos, instrumentales, metodológicos y conceptuales, pero la arquitectura todavía moviéndose en el ámbito de una realidad difusa, a veces de una practicidad extrema, confiando en que ésta nos va a permitir involucrarnos. No estamos, creo, tomando una actitud más activa, más ágil frente a esta avalancha que significa una realidad extremadamente compleja. A ese respecto siempre destaco y tomo como referentes algunos personajes que pasaron una situación más o menos similar a la que estamos experimentando nosotros, allá por el siglo pasado [y antepasado]. A raíz de la revolución industrial hubo quienes tuvieron la capacidad para establecer esa distancia y estableciéndola tuvieron la claridad para entender lo que estaba pasando y entendieron la complejidad que significaba la revolución industrial, empezar a: hacer definiciones, tomar partido, cuestionar sus quehaceres, reflexionar sobre los soportes en los cuales tradicionalmente se habían estado moviendo.

Yo admiro, por ejemplo, a Robert Owen ${ }^{3}$. Un personaje que siendo obrero revolucionó lo que significó el movimiento social, incluso los economistas y urbanistas lo toman como referente. Me asombra por ejemplo, el movimiento de las vanguardias que fueron capaces de entender, con su sensibilidad, la complejidad que se les venía encima, sumergiéndose en su mundo para tratar de reflexionar desde el interior mismo de sus quehaceres y avanzar, no preocupados de lo que les exigía inmediatamente la sociedad afuera, sino desde sus disciplinas, incluso separándose de la contingencia.

Había algunos arquitectos que, en determinado momento, no les interesaba prioritariamente construir, pero si les interesaba reflexionar sobre lo que realmente estaban haciendo. El mismo Le Corbusier ${ }^{4}$ da muestras de aquello. Hoy día lo criticamos o lo aplaudimos, pero en su momento tuvo la capacidad para tener un discurso seguro y coherente frente a la realidad compleja de su contemporaneidad. Creo que a nosotros lo que nos está faltando es tener esa claridad para establecer las distancias necesarias, asumir esa complejidad y poder reflejarla desde el punto de vista de cada uno de nuestros roles: academia, profesión, gestión, administración, etc., frente a eso, uno de los temas que 


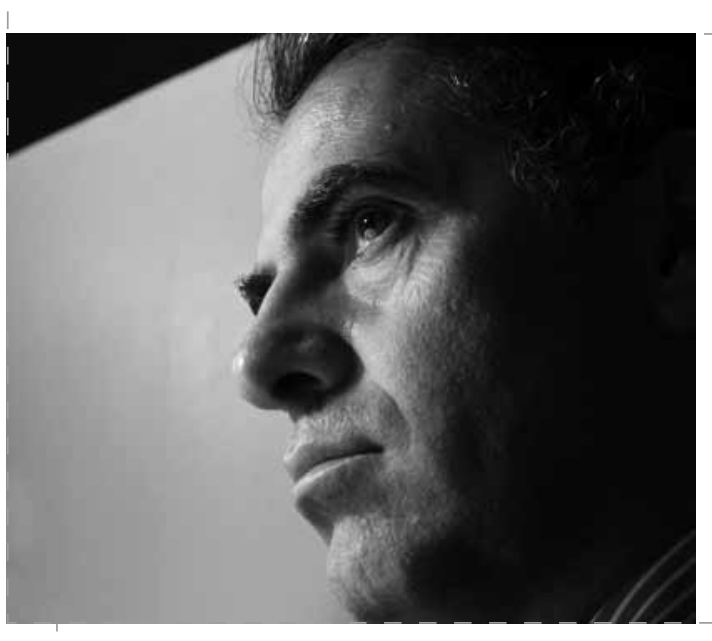

me llama la atención es que no hemos sido capaces -en el siglo xx- de reflexionar sobre nuestro quehacer ni de consignarlo.

A mí me llama la atención qué no hay una gran historia de la arquitectura ni del urbanismo chilenos ¿Por qué no hay registros que den cuenta de esa reflexión, que desde el hacer de cada uno de los arquitectos se podría ir construyendo? Eso yo lo asocio con la academia. Todos estamos de acuerdo que el Taller ${ }^{5}$ es el elemento central de la docencia, siempre que de cuenta realmente de esa reflexión que todos los profesionales deberíamos hacer en el marco de esa complejidad, tratando realmente de avanzar en la construcción de nuevos: soportes, posturas, metodologías, nuevas interpretaciones y propuestas de la realidad. Al respecto estoy convencido de que hay otros ámbitos, hay otras áreas que podrían aportar algunas luces, caminos, reflexiones, que permitirían incorporarlos a nuestro quehacer para tener algo que decir.

De repente, estamos más preocupados del objeto y menos de reflexionar sobre cuál ha sido su proceso de construcción, concibiéndolo independiente de éste sin asumir que el objeto arquitectónico es su resultado y consecuencia. Esto es complejo, un proceso que es necesario de analizar, reflexionar, registrar y cuestionar para poder ir avanzando en el conocimiento.

Llama mucho la atención, por ejemplo, todos esos movimientos del siglo pasado: el impresionismo, simbolismo, modernismo... cuánto nos han aportado para avanzar en el conocimiento y en el desarrollo de la arquitectura. Sin embargo, hoy en día todavía estamos en un período de construcción [de una cosmovisión] ${ }^{6}$, hay un poquito de inseguridad y desorientación frente a la avalancha que significa una realidad compleja y extremadamente cambiante. No es fácil tomar esa distancia, tener claridad de hacia donde vamos, tener la capacidad de construir nuevos soportes, tener esa capacidad interpelativa de una realidad que nos proporciona seguridad y tranquilidad, que nos da ciertas bases para poder ejercer nuestra profesión, la que sin embargo es necesario cuestionar, interpelar, y sobre la que debemos reflexionar.

(Se integra Verónica Serrano al panel).

\section{Generalistas y especialistas}

/ LP: Ahora, refiriéndome a lo que significa nuestra carrera, creo que es inconcebible que de alguna forma todavía no tenemos claro lo que es la especialidad; seguimos siendo una carrera muy generalista, lo que a lo mejor es algo propio del arquitecto.

/ PM: Te interrumpo... mi posición es que ojalá nunca nos convirtamos en especialidad.

I LP: Pero en alguna forma se da y se va a seguir dando. Una persona que se dedica a la iluminación lo hace mucho mejor si realmente se dedica a [eso]. Lo conversábamos con otro profesor... hay muchos arquitectos que terminan derivando en construcción y lo ven como una cosa negativa [porque no se sienten formados para eso].

/ PM: Pero ese es un proceso natural que la sociedad regula, pero la academia -desde mi punto de vista- no debiera formar especialidades. Hay países en que las escuelas de arquitectura forman el arquitecto: aparejador, estructuralista, etc. De acuerdo a lo que me ha tocado a mí en la vida profesional -y aquí me voy para el otro lado- una de las gracias que tenemos los arquitectos es esa capacidad de enfrentar cualquier problema, de estudiarlo, de meternos en profundidad y de aprenderlo. Yo siempre le digo a mis clientes: no tengan miedo. A veces los clientes son temerosos porque uno no ha hecho nunca, por ejemplo, una clínica, y les digo, justamente a nosotros nos formaron para enfrentar problemas y meternos, y conocerlos, tenemos esa capacidad.

/ LP: Pero tocando ese mismo punto, para poder hacer un hospital X, tú tienes que tener un currículum suficiente, de hecho, este es uno de los problemas que nosotros hemos visto en el campo profesional: que para poder diseñar, por ejemplo, un hospital, tienes que haber hecho antes un hospital, y ese es un círculo vicioso.

/ VS: Pero es evidente que proyectos de esa magnitud no sólo requieren de especialización, sino que requieren un equipo [interdisciplinario]. Uno podrá tener un líder de equipo, que va a tener metros ${ }^{7}$ y metros de especialidades en esa área, pero para abajo, creo que no necesariamente va a necesitar especialistas de cada uno de los temas, sino que el equipo tiene que ver cuál es el desafío y cómo se arma para enfrentarlo.

/ LP: Es tan cierto lo que tú dices en términos generalistas, que ustedes mismos a través de las propuestas del Ministerio de Obras Públicas ${ }^{8}$, el que hace de cabeza es el arquitecto. Eso te demuestra que es una persona que tiene que tener la capacidad de liderar a un grupo.

\footnotetext{
"Taller" es la única asignatura transversal de la carrera de arquitectura en la FAU/UCh. En ella los alumnos realizan proyectos guiados por arquitectos.

6 N. de R.

Los metros cuadrados $\left(\mathrm{m}^{2}\right)$ construidos son parte importante del currículum de un arquitecto.

8 Ministerio de Obras Públicas (MOP).
} 


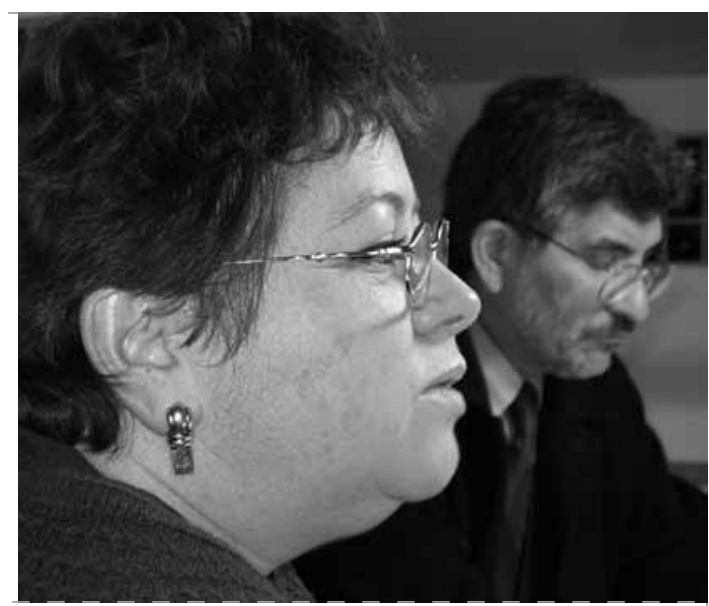

IVS: ¿Sabes?, yo tengo una visión distinta, quizás otro enfoque de lo que ustedes están planteando. Es lo siguiente:

Tengo una hija que está a punto de entrar a la universidad y está muy angustiada, con la típica angustia que tienen todos los niños en esta etapa. Yo le he dicho que se relaje, porque hoy día la educación es construir conocimiento y uno tiene que estar abierto a todas las posibilidades. Me refiero a que eso de que uno nació para ser arquitecto, estudió arquitectura y creyó que siempre iba sólo a diseñar arquitectura es algo que me parece fantástico en sí mismo, pero creo que hoy en día es muy importante que las universidades en general, y todas sus carreras, planteen su educación de manera que le den herramientas y elementos a las personas para poder moverse en la diversidad, o sea, ¿Qué le reclamo a veces a las universidades?, por ejemplo a la Facultad de Arquitectura. Nunca tuve (no sé como serán las mallas curriculares ahora) ramos de: liderazgo, emprendimiento, de formación de equipo, todo ese tipo de cosas. Hoy, esa tendencia de que el arquitecto está en su escritorio esperando que le llegue un encargo ya no existe; a los que están en eso no les va a funcionar.

El arquitecto debe tener la capacidad de prever cuáles son los temas de futuro, idear soluciones que no son solamente arquitectónicas, sino una solución integral que tiene un componente arquitectónico. Uno tiene que formar parte de la solución integral y después bajar con su propio expertise a la cosa arquitectónica. Yo creo que eso es fundamental hoy día.

\section{La construcción de un discurso disciplinar}

I EC: Cuando planteo que realmente nos cuesta asumir el tema de la complejidad, se traduce, por ejemplo, en lo siguiente: hay que tener claridad para definir cuáles son las competencias en el ámbito disciplinar, generales o secundarias.

En el marco de las competencias secundarias podría estar esas aptitudes de: formar equipo, comunicarse, liderar, dialogar con otros profesionales, entender un mundo que se mueve bajo ciertas leyes (de mercado, las Ilaman algunos), gestión, administración, entre otras.

Pero yo creo que son más importantes las competencias del ámbito disciplinar, creo que allí todavía no tenemos claridad de cuáles son las nuevas competencias en el ámbito de la disciplina que tenemos que ir desarrollando, porque ellas han cambiado, porque se han modificado las distintas concepciones de: espacio, función, usuario, etcétera.

¿Por dónde se canaliza el desarrollo de esas competencias disciplinares? ¿En el taller?

Proyectando la acción del taller.

¿En dónde se deberían desarrollar las competencias disciplinares?

\section{En pregrado.}

¿En dónde deberían desarrollarse las competencias complementarias?

\section{En posgrado.}

En el taller de pregrado deberían desarrollarse las competencias disciplinares, entendiéndolo en un amplio sentido como la principal instancia de discusión y de confrontación de posturas, pero eso significa también repensar un poquito la estructura del taller. Se han hecho algunos avances, pero es allí donde se deben poner en juego las nuevas posturas, tratando de desarrollar competencias disciplinares.

\section{El arquitecto contemporáneo debe} tener la capacidad de contactarse con otros profesionales, pero eso lo puede desarrollar en la formación de posgrado, con otra perspectiva, orientado a la especialización. No creo mucho en la especialización, pero es allí en donde deberían manejarse ese tipo de competencias que son indispensables, pero creo que ellas están al servicio del despliegue de un discurso disciplinar que debe idealmente desarrollarse, extenderse y buscarse, en pregrado, en el taller. Es allí donde hemos ido reduciendo las posibilidades de tener esa capacidad para construir y desarrollar competencias nuevas, que tengan que ver con: la disciplina y con el manejo que debemos tener para no ir renunciando a lo que nos es propio, porque estamos frente a ese gran dilema.

Por eso planteaba que me daba un poco de susto conversar estos temas, porque esa realidad compleja nos exige un compromiso mucho mayor de los que hemos asumido, porque realmente estamos en una realidad extremadamente incierta en el sentido de vernos superados por ella y al mismo tiempo por otros ámbitos disciplinares que nos están restando quehaceres que nos eran propios. Esto es en parte por esa falta de claridad.

Yo pongo mucho énfasis en esas competencias disciplinares por mi sesgo académico; las otras las acepto y las creo indispensables, pero: ¿Podrían servirnos para realmente reestructurar la propuesta académica en pre y posgrado? ¿Qué significa pregrado? ¿Cuál es el énfasis que deberíamos tener? ¿Qué debería desarrollar el pregrado?

En esa medida, incluso vale la pena pensar la posibilidad de acortar pregrado, centrando su misión fundamental en el desarrollo de competencias disciplinares. Esto significa: una construcción previa, nuevos soportes epistemológicos, inventar metodologías, reformular el taller, incorporar nuevos profesionales, poner en juego en el taller (instancia básica para los estudiantes de arquitectura) todos aquellos conflictos y presiones que desde el ámbito de la disciplina y del conocimiento se están generando, y que fuera de nuestro espacio se están canalizando de manera mucho más adecuada. 


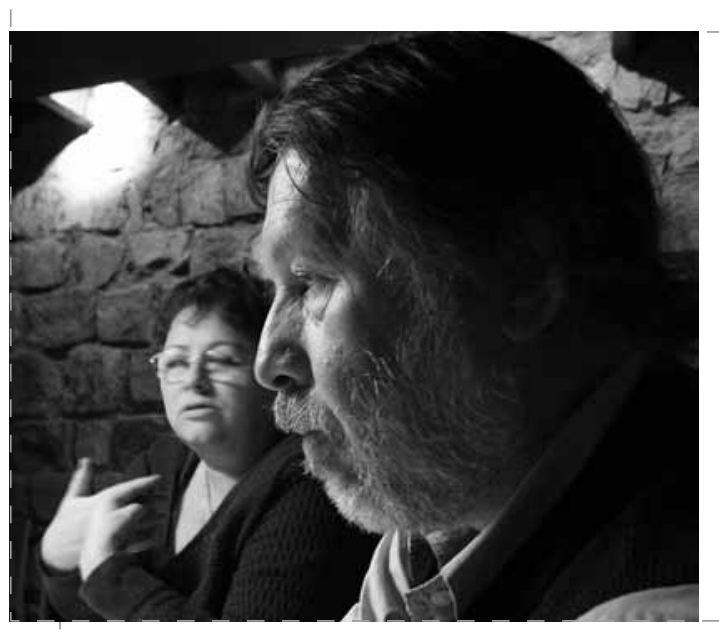

No debería llamar la atención que oficinas de arquitectura inviten un filósofo a que les entregue ciertos fundamentos a sus proyectos o que trabajen con antropólogos, o que éstos estén hablando más del espacio y de la ciudad que los propios arquitectos. Ahí podemos estar perdiendo terreno, porque no tenemos la claridad para asumir la complejidad.

I VS: Yo lo veo más como un asunto de énfasis que de compartimentos estancos. Le tengo terror a los compartimentos. Es decir, creo que la visión de trabajar ampliando la mirada, sin perder de vista quién es uno y cuál es el rol que uno tiene, es en definitiva el desafío. Ahora, en las distintas etapas formativas uno podría generar ciertos énfasis en algunas cosas, pero creo que desde el colegio, ojalá tuviéramos esa mirada, de que el mundo ya no se va a construir desde un solo punto de vista.

/ PM: Coincido contigo Verónica en el sentido que entiendo tu preocupación. Sería terrible que la academia se quedara con el sistema, sin embargo la definición de nuestra profesión, de nuestro saber, de nuestra disciplina, tiene un componente básico que es la creación. La creación, o el taller, es en lo esencial lo mismo hoy que en el pasado, con las complejidades por supuesto que hay hoy día.

Ojalá la arquitectura no perdiera nunca esa condición de disciplina creativa que tiene que ver con el habitar y la construcción de espacios. La especialización, las profundizaciones, de las competencias disciplinares, debería ser un tema para después, en la etapa de posgrado. No estoy de acuerdo con achicar el pregrado, yo creo que en la medida que haya más entrenamiento creativo, más entrenamiento entendido como estar más años dedicado exclusivamente a crear, a entrenarse con el espacio y a especular con el espacio, eso nunca va a quedar obsoleto, porque es inherente a la esencia de nuestra profesión. Veo por tanto las competencias disciplinares más relacionadas con el posgrado.

\section{/ LP: Lo integral cuesta mucho.}

/ PM: Yo estoy relacionado con distintas actividades, hago clases en la Universidad del Desarrollo en Concepción, y veo otras visiones las visiones de la formación privada que creo -como decía al principio- nos van a obligar, a las tradicionales, a competir con ellas y a irnos subiendo al carro de toda esta complejidad.

\section{Arquitectura y posgrados}

/ LP: Pero fíjate que yo pienso que si bien nosotros vamos a tener que competir con las privadas, creo que vamos a tener que valorar lo que nosotros somos, que tenemos fortalezas sobre las privadas, y entre ellas creo que están los posgrados.

Una privada no puede hacer un posgrado tan fácilmente como lo podríamos hacer nosotros, en el sentido que tenemos proyección, tenemos tiempo. Yo estoy de acuerdo contigo respecto al taller en términos de no perder su esencia, sin embargo, es muy difícil integrar otras especialidades porque integrar significa también saber recibir al que viene. En nuestra escuela en los semestres avanzados de la carrera se ha tratado de invitar a profesores de otras especialidades, y los mismos alumnos a veces no los toman, porque hay una persona que está integrando, que es el generalista, que es su profesor de taller. Entonces no es tan fácil la explicación. Ahora, en la vida profesional, también trabajamos integrando. Trabajamos integrando ingenieros, otros especialistas u otros arquitectos, es muy raro hoy día el arquitecto que ejerce solo, hoy día el arquitecto va a trabajar con más personas, por lo tanto creo que eso también es parte de la enseñanza que tenemos que entregar.
I VS: Ahora, fíjate que yo también pienso en cómo se podría construir una carrera. Si a mí me tocara hoy día estudiar de nuevo estudiaría una carrera distinta. No para perder todo lo que soy sino que le sumaría otra mirada a lo que yo ya tengo instalado como mí tema. Pienso que arquitectura debería ser capaz de abrir esa mirada también. A la luz de las conversaciones que tengo con mi hija (perdonen lo anecdótico y autorreferente), le digo: si a ti te gusta el diseño, diseño sólo no te va a servir, pero piensa qué otra cosa más te gusta. Entonces le digo: vas a tener que armar dos o tres carreras o componentes para hacerte distinta, o sea tú vas a tener que aportar una cosa distinta, y yo creo que arquitectura debería ser capaz también de acoger, por ejemplo, especialistas en temas comunicacionales vinculados al tema del espacio, la ciudad, la arquitectura. ¿Por qué no están presentes?

/ LP: En relación a lo que tú dices, los alumnos sobre todo cuando están saliendo, sienten lo mismo, ven la necesidad de ser distintos, de buscar alternativas. En una conversación con algunos ex alumnos, tiempo atrás, me comentaban que para ellos habían sido muy importantes las nuevas formas de comunicación, los 3D, las imágenes virtuales, porque veían que era una posibilidad también de un campo nuevo. Pero se dieron cuenta que ya todos lo tenían, y dijeron: ahora ya no somos diferentes, porque ya todos lo manejan. Es decir lo que un momento dado fue, ya cambió. Entonces yo creo que una virtud, como tú dijiste al comienzo, que tiene que tener la universidad, es abrir, abrir posibilidades y no quedarse estancados en una sola área.

IVS: O sea, [lo veo] como un desafío de aprendizaje, no una cuestión de cultura general. Cómo desde nuestra profesión se trabaja [determinado] tema, o cómo la gente que trabaja ese tema puede tener un complemento, un punto de vista 


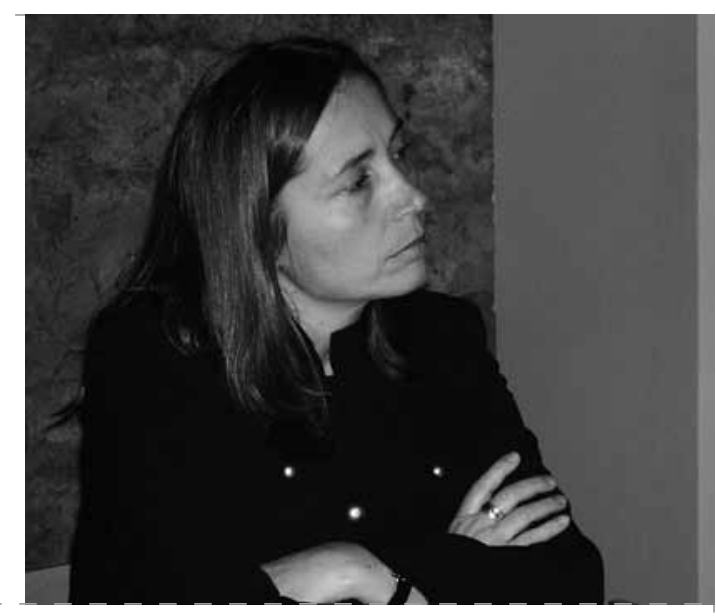

arquitectónico, urbano, para nutrirse, para volver a su tarea...

/ PM: Ese es un desafío muy grande, porque el Saber es muy amplio, y nosotros tenemos una tendencia generalista a quererlo todo y entonces se corre el riesgo desde el punto de vista de una facultad, de desperfilarse en la esencia. Por eso uno de los temas relevantes es el del posgrado. La facultad de arquitectura debiera desarrollar un programa de posgrado de un nivel altísimo y de un espectro lo más amplio posible.

I VS: Como me ha tocado mucho estar en el sector público, yo creo que hay una distancia muy grande cuando el territorio es totalmente común. Los arquitectos construyen sobre un territorio normado y definido vocacionalmente desde el sector público, y vienen sólo como contraparte, sin conocer cómo: se toman las decisiones, se organizan, se pueden cambiar, se priorizan los temas [en el sector público], entonces viene simplemente a enterarse, como quien dice, a pedir la boleta del informe...

/ MP: Pero eso no pasa sólo con los arquitectos, eso le pasa a todos los que están ligados al [sector] inmobiliario, a la construcción, a los ingenieros.

IVS: A eso me refiero... lo que quiero decir es que creo que sería importante generar un vínculo más estrecho entre ambos territorios.

Tengo una experiencia bien bonita: yo fu a hacer un proyecto desde el sector público, pero nosotros sabíamos que si lo hacíamos sólo desde el sector público no iba a tener credibilidad, y para nosotros era importante hacerlo, y convocamos a cuatro universidades. La conversación que sostuvimos con las universidades fue: mire, nosotros esperamos que ustedes no tengan ninguna censura respecto de lo que vienen a imaginarse, pero el compromiso es que después de terminado el trabajo ustedes entiendan que el quehacer público tiene estos tiempos, etapas, compromisos, recursos. Dígannos como vamos a bajar esto a nuestro hacer público... y fue una tarea bonita, porque permitió una mirada bien amplia y después las bajadas en unos conceptos mucho más precisos, pero con un nivel de sintonía fina más armónico.

I LP: Fíjate que yo creo que se da mucho eso que dices en los proyectos referenciales, los que van a concesiones. Hay una relación porque ya no es un proyecto que YO hago...

/ PM: ...eso es muy importante porque lo que tú estás planteando es una estrategia de administración del Estado distinta, porque antes era impensable una cosa así.

I VS: En definitiva el Estado también ha cambiado... en el mundo todos cambian (...) entonces se da esta situación de encuentro, de entenderse con el otro rápido. Ahora, como Dirección de Arquitectura en el Ministerio, hemos tratado de instalar la filosofía de que esto es la solución a un problema, y que el problema es mucho más integral incluso que la edificación en sí misma. No sólo tiene que ser buena arquitectura, sino que tiene que ser oportuna, tiene que estar dentro de los montos y recursos disponibles, tiene que ser integral, sinérgica con las otras cosas que están pasando desde el Estado... y no siempre es así, quizás de repente el tema sólo es la edificación, que sea muy buena como respuesta arquitectónica y nada más. Hoy día esa cuestión no es suficiente.

/ LP: Sí, y eso va muy relacionado a nuestra formación, porque eso nosotros no lo tocamos nunca, generalmente interesa el resultado como arquitectura.

I MP: Creo que [esa] mirada tiene mucha relación con la visión académica, porque los estudiantes lo perciben de otra manera.
Yo creo que los estudiantes saben esto, que reclamaba Verónica hace un minuto, de armar equipos. Yo creo que los arquitectos (y a mí me ha tocado en un posgrado donde hay arquitectos, ingenieros, constructores, comerciales, industriales) lideran equipos, y los lideran precisamente porque tienen la capacidad de ser generalistas. No [están] encerrados en una sola visión, o sea, están formados en el trabajar en equipo, saben lo que es compartir cosas, no son egoístas, son mucho más generosos que otros profesionales que vienen con una estructura de individualismo absoluto. El tema de liderar equipos, reconociendo que somos débiles en los aspectos: financieros, económicos, normativos... pero precisamente capaces de reconocer esa debilidad, nos hace fuertes dentro de un equipo.

En el magíster la gente se organiza en equipos, y siempre terminan los arquitectos liderándolos aunque son los que menos saben en profundidad de cada uno de los temas, pero sí los que conocen todo el espectro o al menos han oído de él.

Creo que la Facultad, nosotros, a nivel de pregrado podemos ser muy críticos en muchas cuestiones, pero creo que en la formación, desde que yo la conozco, hay ciertos valores que se mantienen y que son intransables. La importancia del taller [está en] la versatilidad, la flexibilidad, el que un profesor hable y diga blanco, y que el profesor del siguiente semestre le diga negro, y que el estudiante sea capaz de adaptarse a ese blanco y negro es una cuestión que te hace endurecer la piel y estar dispuesto a recibir el rechazo y a recibir el abrazo del éxito. En ese sentido creo que nuestros alumnos siguen formándose de la misma manera, siguen siendo capaces de absorber, de ser muy esponja.

Nos hemos quedado en cuestiones que son propias de la mirada romántica y ahí es donde está la debilidad, en seguir pensando que lo que hay que enseñar es urbanismo, construcción, arquitectura e historia, y seguir 
pensando que esas cuatro áreas tienen que ir cada una con 4,5 horas a la semana los lunes y miércoles, y seguir estudiando la misma historia, a la vez que te encuentras con que hay medios en que la historia de la arquitectura, por ejemplo, está disponible, y la podrías absorber en mucho menos tiempo. Quizás Teoría da para madurar en más tiempo, conceptos que son mucho más profundos, que requieren una mirada más transversal, más interdisciplinar con filosofía, antropología, etc. Hay [cosas] que deberían ser mucho más rápidas, más eficientes y dejar espacio a cuestiones nuevas. [Hace 15 años instalábamos CAD, pero ahora ya no es necesario el mismo énfasis. Imaginemos una malla curricular flexible que dé cabida a asignaturas que son necesarias hoy, no ayer ni en 15 años].

/ EC: Eso nos confirma dos cosas: primero, hay muchos problemas que nos están acosando, hemos mencionado varios; segundo, lo más importante de este escenario es la consolidación disciplinar. Esas otras competencias, las vamos a adquirir o van a pasar, pero a lo que no podemos renunciar, es a tener claridad en nuestro discurso disciplinar Por eso me refería que lo fundamental es lo formativo del pregrado, porque él representa las bases disciplinares de ese discurso que nos hace únicos y nos permite todo lo demás, como por ejemplo, tener la capacidad de discutir con el otro.

En el proceso comunicativo tiene que haber aptitud para transmitir un mensaje, si no se tiene esa competencia, si no se tiene mensaje, se puede tener los medios, pero ello no asegura la posibilidad de transmitir aquello que estoy intentando hacer. De allí que yo mencionaba que el pregrado tiene que ser intenso en esa capacidad para ir construyendo un discurso. Porque además enfrentaríamos el gran beneficio, pero a la vez la gran desventaja, de no disponer de discursos establecidos, lo cual nos plantea el desafío constante de ir construyéndolo.

I VS: Yo creo que ese es un punto central, porque en el fondo, el arquitecto tendría que ser formado en tener habilidades para captar... no es tener un discurso per se, es tener las habilidades para captar cómo y cuáles son las verdades que se van construyendo en forma social, que son dinámicas. No existen ya los paradigmas per se; a eso me refiero con esta capacidad de [educar en] habilidades más que [en] conocimientos específicos. Las habilidades que se requieren en el mundo son distintas a las que se requerían hace diez años, o hace veinte. A mí me toca casi, ser cliente de los arquitectos, en el fondo yo les planteo mi tema y ellos lo tienen que satisfacer, y de verdad que de repente hay un desencuentro en la comprensión de los requerimientos, porque a veces se entienden como un requerimiento arquitectónico, un requerimiento espacial, y es más que eso.

Hoy, la manera en que los jóvenes se mueven es mucho más abierta... tiene sus problemas también, porque hay una falta de compromiso grande, porque como todo puede caerse, como todo puede cambiar, no se aferran a nada y eso daña a la sociedad. Efectivamente no hay que perder la capacidad de compromiso, pero no hay que tener ningún temor a decir: mira, la verdad la construimos entre todos, y hoy día estoy sentada en esta mesa, y mañana estaré en otra, y así vamos a hacerlo con humildad si tú quieres, pero con buenas herramientas de diálogo.

I EC: Yo creo que es fundamental en esa construcción del discurso nuestro, la reflexión. No puede haber discurso sin reflexión, insisto, en términos del proceso de construcción de objeto de la arquitectura en donde la obra es una etapa, es esa fase que realmente da cuenta de cómo se ha ido construyendo ese proceso... y en él está la complejidad que nos permitiría comprenderla.

En relación con mi percepción general de lo que significa la enseñanza de la arquitectura y sin referirme a ninguna universidad en particular: hay un libro que se llama "la historia de la profesión del arquitecto" ", y que hace una revisión desde los griegos de cómo se concibió, quienes eran arquitectos, que rol tenían en la sociedad, etc. Al revisar ese libro uno se da cuenta como ha ido perdiendo terreno el arquitecto. Lógico que los tiempos han cambiado, pero de ser casi considerado un dios, que daba cuenta de cómo debería ser la casa de los dioses en la sociedad griega, ha ido perdiendo terreno hasta en este momento ser uno más.

La sociedad hoy es distinta, es dispersa, es más compleja. Las especializaciones se han ampliado, pero más que ese rol específico que puede estar jugando el arquitecto hoy en la sociedad, a mí lo que me llama la atención, es cómo ha ido desvirtuándose ese discurso que daba cuenta de nuestra condición de arquitectos, y también me llama la atención cómo se ha ido (esta es una interpretación mía, puedo estar muy equivocado) perdiendo uno de los aspectos esenciales en el ejercicio de nuestra profesión, me refiero a el hombre, y ¿cuál es la concepción de hombre que tenemos hoy en día?, ¿cómo podría la arquitectura contribuir a la construcción de un ser humano?, y frente a esa definición de hombre, ¿cómo estamos construyendo su hábitat?

Hoy día el hombre es un cliente, en tanto ese hombre se traduce en capacidad de UF ${ }^{10}$ para poder adquirir tal o cual hábitat. Nuevamente regreso a Owen, quien decía que el hombre es ese ser que debería propender al "equilibrio intelectual, físico y moral," uno podía estar de acuerdo o no, pero ese era el punto de partida. Su libro empieza definiendo aquello. El mismo Le Corbusier, equivocado o no, tuvo una concepción del hombre hacia el cual orienta todo su quehacer arquitectónico. Podríamos revisar cómo unos cuantos más se comprometen con una definición hasta esa dificultad tenemos hoy, porque es muy complejo, el hombre va cambiando, establece otras relaciones con su entorno, con sus pares. Somos verdaderas cápsulas de individualidades.

Hay problemas, hay nuevos escenarios, se requieren nuevas definiciones, pero de repente la dinámica de la contingencia nos impide tener esos espacios de reflexión que nos permitan tomar ciertas definiciones que vayan a sustentar nuestro discurso arquitectónico. Creo que uno de los roles que debe tener la universidad es ese.

\section{Arquitectura en el sector públ ico}

/ LP: En relación al tema de la revista, que es Grandes Operadores - Pequeños Negocios, y pensando que generalmente es el Estado y sus instituciones las que trabajan las grandes operaciones, me gustaría que tú [Verónica], nos contaras tu experiencia.

Spiro Kostof. "El arquitecto: Historia de una profesión".

10 Unidad de Fomento (UF), unidad monetaria ajustable de acuerdo a la inflación, creada en 1965 


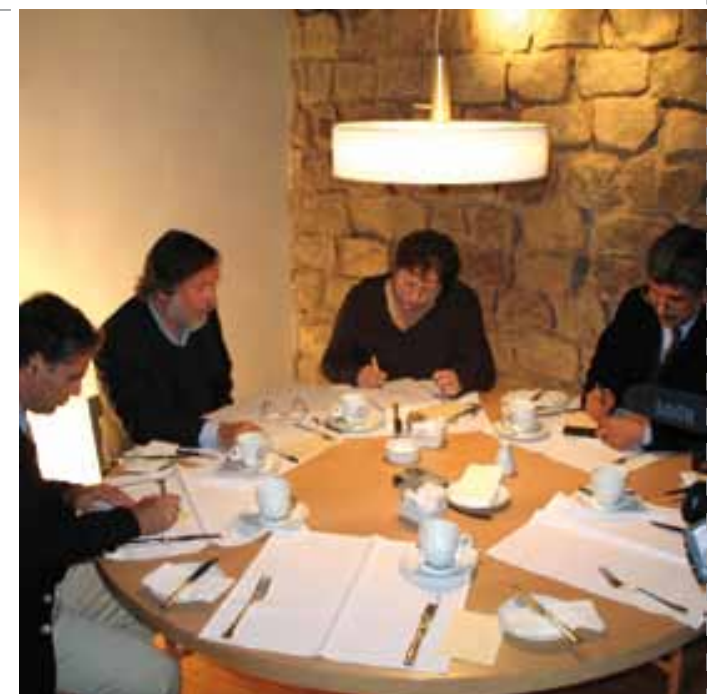

Recuerdo que uno de los primeros trabajos que me tocó saliendo de la universidad fue generar poblaciones de dos mil ochocientas personas para la CORVI ${ }^{11}$ y te llegaba un proyecto que era enorme y no tenía la reflexión que tú planteas, sino que había que hacerlo no más, había que trabajar con lo que tú sabías, con lo que tú habías aprendido y con lo que habías visto de compañeros tuyos. Tenías que tomar decisiones y no tenías conciencia de lo que estabas haciendo, porque realmente era crear un paño grande de ciudad en la ciudad... bueno, eso es hoy día de alguna forma generado más por la empresa privada que antes, pero también el Estado tiene un rol muy fuerte en las grandes operaciones.

/ VS: Sí, lo que ocurre en definitiva es que mientras nosotros estamos teniendo esta discusión, hay unos requerimientos muy dispares en esta sociedad. Todavía no estamos en una situación en que podamos reflexionar sobre esos vínculos, en esta reflexión del tipo de sociedad que queremos construir, el tipo de hombre... cuando tenemos gente que hoy día está en una situación de precariedad muy alta. [Esta es] entonces una situación de transición, es como esos niños que cada vez que pasan por un umbral se pegan porque no se han dado cuenta que crecieron y todavía no se manejan.

Estamos en una clara situación de transición hoy día, pero no podemos hacer cuenta que este problema social inminente no está ahí y por lo tanto, bien o mal, hay que resolverlo... yo creo que se ha encaminado en resolverlo un poco mejor, pero se dista mucho, de lo que querríamos como solución definitiva.

Por otra parte, creo que las soluciones definitivas son relativas, no existe lo definitivo porque las ciudades ya tienen incorporadas hace rato la posibilidad de ir cambiando, pero yo creo que no vamos a poder evitar que ( $y$ en más de una oportunidad) nos duela saber [que] no es lo óptimo, pero es lo necesario y esa es una decisión que hay que tomar a conciencia pero mirando otros componentes.

A mí me correspondió, como SEREMI ${ }^{12}$ de Vivienda reflexionar en ese sentido, porque cuando te encuentras con el dolor de las personas... te voy a dar un ejemplo que para mí fue dramático... el tema del Volcán ${ }^{13}$ en Puente Alto. [Esas son] las casas más vapuleadas en Chile, la población menos atractiva desde el punto de vista espacial, urbano; y resulta que había gente arriba de un techo amenazando quemarse a lo bonzo porque no le estaban dando esa casa. Esa es la visión... [por un lado están] esos señores que querían esa casa sí o sí, y mucha gente que dice "¿cómo es posible que se construyan esas casas?" ¿Te fijas?... estamos viviendo en esa realidad.

/ MP: Bueno, ahí viene un tema que yo creo que es importante mencionar... si bien es cierto nuestra formación tiende a ser muy amplia y generalista, es también sesgada. Es sesgada por que no considera ese aspecto que tú estás mencionando: la vivienda social no es un tema de nuestra Facultad; existe un
Instituto de la Vivienda ${ }^{14}$, pero, por ejemplo, en proyecto de título ¿cuántas viviendas sociales se hacen?, en los talleres de pregrado: ¿quiénes se dedican al tema de vivienda social?, y ese es un tremendo tema... ¿cuál es la cantidad de viviendas sociales que se entregan?, pensando en la vivienda social que cuesta menos que cuatrocientas UF ${ }^{15}$ ¿Cuántas son las que se entregan anualmente versus las otras?, ¿cuál es la cantidad?, no de montos de inversión, ni de precios de transacción, sino en cantidades: ¿cuántas son las viviendas de menos de cuatrocientas UF? ¿cuántas son las viviendas de hasta dos mil UF?, ¿cuántas son las de cinco mil y cuántas son las de doce mil?

En nuestro Plan de Estudio y en nuestros talleres cuando se hace vivienda se hace la de doce mil [UF] ${ }^{16}$, y la social NO (se ha hecho uno que otro concurso, eventualmente, y con muy pocas ganas de los estudiantes). No motivamos [a los alumnos] diciéndoles: mira, aquí hay un temazo, que estamos criticando [siempre], pero no tenemos derecho a hacerlo porque no participamos de ese nicho y sabemos que es un nicho súper competitivo, en donde hay importantes recursos involucrados, que financieramente no deja de ser [importante].

/ VS: Quizás estoy hilando demasiado fino, pero creo que aquí hay pérdida de un compromiso político. La palabra política es una palabra muy buena. Lo que me complica es que haya gente que sólo ve el resultado físico y que le interesa más ver el problema

11 Corporación de la Vivienda. En 1976 se funde con la Corporación de Servicios Habitacionales (CORHABIT), la de Mejoramiento Urbano (CORMU), y la de Obras Urbanas (COU), siendo reemplazados por el Servicio Regional de Vivienda y Urbanización (SERVIU).

12 Secretaria Regional Ministerial.

13 Generalmente al hablar de el Volcán, se hace referencia a las villas Volcán San José I, II y II. Puente Alto, Santiago.

14 INVI.

15400 UF = US\$13.200, aproximado, al 30/06/06

$16 \quad 12.000 \mathrm{UF}=$ US $\$ 400.000$, aproximado, al 30/06/06 


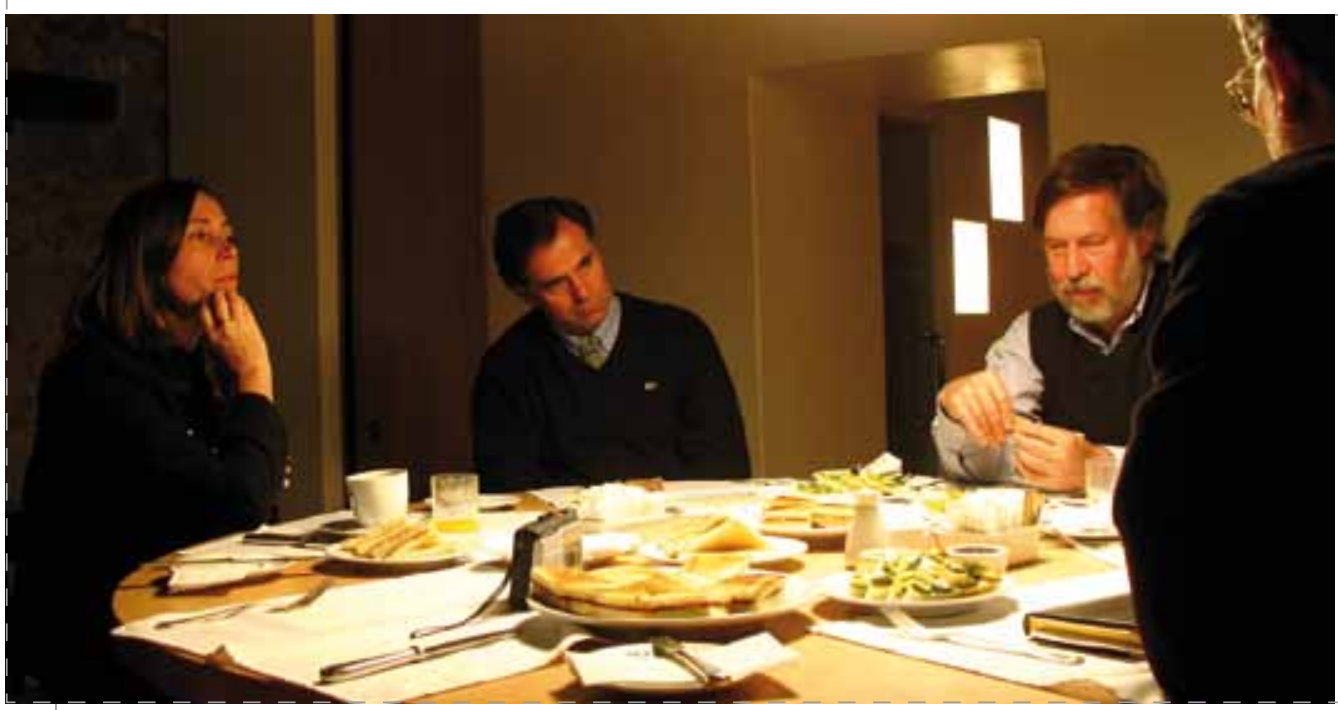

como dimensión y desplazamiento, y no como problema social... si una persona no tiene casa se le va a enfermar el hijo... todo ese conjunto de temas no están vistos, no hay cercanía, a eso me refiero con falta de compromiso político. Yo creo que las universidades también pecan un poquito de ello, con toda sinceridad creo que hay un alto interés en el objeto... puede ser que hoy día estemos en una crisis de identidad, antes era más claro.

\section{Sí, defiendo el tener un compromiso.}

/ LP: La Facultad tiene al Instituto de la Vivienda ${ }^{17}$ que de alguna manera ha incentivado el tema de la vivienda, el cual es complejo, por lo que se privilegian programas que son de menor compromiso y también más fáciles de transmitir. No llegan a un proyecto de vivienda social si es que no lo han estudiado antes y conocen previamente la materia.

Tengo anotados algunos puntos que sería importante que pudiéramos tocar...

\section{Especial izaciones}

/ MP: Espera, yo quería referirme a un tema que tocamos hace un momento: las especialidades. Éstas no corresponden al pregrado, creo que son de posgrado, y la tendencia debiera ser igual que en otras profesiones. Quien egresa de pregrado es un generalista. En posgrado hay algunos que se pueden especializar y seguir siendo generalistas, como ocurre con los médicos internistas, y otros tendrán la especialidad, y la especialidad viene dada un poco por las oportunidades.

\footnotetext{
17 INVI. www.invi.uchile.cl
}

Nosotros tenemos en la Facultad la oferta más grande de posgrados, creo, que tiene cualquier universidad en el área de arquitectura: ocho diplomas, dos postítulos, tres magíster, y un cuarto que vendrá en uno o dos meses más. En el fondo lo que estamos haciendo es abrir las posibilidades a todo aquello que a la gente le pueda interesar. Antes la gente que venía a los posgrados era gente que ya había trabajado un tiempo, que venía de estar un tiempo en la calle, que había descubierto que necesitaba algo. Hoy no es así, el alumno sale de pregrado e ingresa inmediatamente a posgrado, sin pasar por la calle. ¿Por qué?, ¿cuál es el argumento?, tengo que seguir armándome, tengo herramientas pero ¿cómo las uso?, ¿qué me está demandando hoy día la calle?, y así hay alumnos que pasan de la una a la otra. Tengo alumnos que hicieron el magíster de urbanismo y luego el magíster de administración y dirección de proyectos inmobiliarios ¿por qué?, porque dicen no basta con el magíster de urbanismo, necesito este otro más.

Tenemos gente que hace el diploma uno, diploma dos y diploma tres, y barre tres ambientes, necesita más herramientas. El promedio de edad es cada vez más joven. La primera vez que me tocó a mí revisar el promedio de edad andaba por los 40+, ahora anda por los 28 , y dentro de eso hay gente que tiene 24 años y está recién titulada y gente recién licenciada, o sea, que recién terminó el cuarto año, hizo parte del quinto y antes de hacer el título hizo magíster junto con el quinto, de manera de hacer título junto con la tesis. Entonces estamos hablando de gente que nos están percibiendo de manera distinta de cómo los percibimos a ellos. Ellos saben que hay que especializarse, lo sienten, y si no son ellos, son sus familias que los presionan.

I LP: Yo te voy a rebatir, más bien te voy a plantear lo siguiente como ejemplo: hubo un tiempo que no existía el magíster, y esto es un asunto universal. En mi caso tengo un hijo que estuvo en Lovaina y me contaba de compañeros que se dedicaban exclusivamente a estudiar toda su vida; no están pensando en mejorar para insertarse en la sociedad de trabajo, sino que su vida es el estudio.

/ VS: Bueno, así como la meditación. Hay gente que dedica su vida a meditar, así mismo hay gente que se dedica a [estudiar], yo siento que es [algo] egocéntrico, pero bueno, allá ellos, pero no es lo que la sociedad necesita.

/ MP: La sociedad nos necesita a todos.

I VS: Bueno, pero yo me refiero masivamente, porque es necesario producir algo...

El pensamiento tiene que ser transmitido, si el pensamiento y la reflexión no son transmitidos no existen. Mientras el pensamiento no [se traspasa], no sale de ti, no existe. Conclusión, ese drama es otro tema, el que los jóvenes se quedan eternamente en la casa, sin compromiso político, sin paradigma político, sin interés o causa.

En España, iba a hacer un doctorado mientras vivía allá, [entré] a la universidad y pasaba exactamente lo mismo, con la diferencia que yo era mamá y tenía niños chicos. Iba a clases y no iban los alumnos, a la tercera clase no fue el profesor. Encontré que esto era una broma, mandé una carta de en duros términos a la universidad, y me retiré. Después hice un curso de posgrado que era mucho más específico (al que iban solamente profesionales especialistas) y la gente viajaba de toda España para asistir. [Aprendí mucho] en ese curso, porque la gente venía de sus profesiones - de su desempeño cotidiano- a construir más, en cambio esos otros estudiantes iban más en la línea de armarse 
el currículum, creerán que así [van a tener] más posibilidades de encontrar trabajo, de afirmarse en el mundo laboral y no es así. Hay una cierta cantidad de requerimientos que tú le pides a una persona que se integra, pero cuando está partiendo no es tanto eso, es más bien la capacidad de afiatarse en un equipo, de tener herramientas básicas para aprender con uno también.

I MP: Yo a lo que voy es que hoy día la gente se interesa mucho más, sobre todo en el área de la arquitectura. Los médicos, los científicos, por lo general, si no son doctores no son nadie... en el área de la arquitectura no es así. Sin embargo en los últimos tiempos la gente está mucho más motivada, más interesada, porque lo asume como una necesidad de ínter disciplina, una necesidad desde el punto de vista laboral, de algo que no quedó completo cuando ellos salieron del pregrado.

I VS: Los alumnos y los padres invierten mucho en este tema y después quedan hasta sobre calificados para los requerimientos que existen. ¿Cuáles son los problemas que como sociedad estamos teniendo hoy día?, ¿son efectivamente para que haya tanto magíster?

Seamos humildes como país, digamos que no; creo que requerimos una cierta cantidad de expertos, pero sobre todo [en] temas ya más incorporados a un desarrollo profesional.

/ LP: Si, si no han surgido estos posgrados en hospitales, es porque no son necesarios, si esa es una cosa más bien natural, de alguna manera se va dando una regulación...

I VS: De alguna manera es un expertizaje tan específico, que viene el consultor internacional y hace estos hospitales, porque la globalización existe, y se acabó.

\section{¿Me entiendes?}

/ LP: A veces se cae en errores, porque [por ejemplo] nosotros tuvimos una vez un proyecto que tenía que tener un consultor extranjero y fue un chascarro: el experto extranjero era igual que nosotros, no tenía nada de experto con respecto a nosotros. Creo que eso es un poco de país nuevo y de no confiar, de no darse cuenta que el medio está capacitado.

/ EC: Y a propósito de los posgrados, y sus proyecciones, sin renunciar a nuestra condición de [arquitecto\}, cual es la de proyectar... si a través del área de posgrados, de la adquisición de competencias, de la inserción en el mercado, voy perdiendo mi condición de arquitecto, me transformo en otro profesional. El arquitecto es proyecto, y por supuesto, ahí viene lo de la creatividad -irrenunciable- que le sirve la teoría. Sí, [se] requiere una fundamentación una manera de posicionarse frente al cosmos, sí.... de acuerdo, pero todo eso se tiene que traducir en un proyecto. Que se construya el proyecto, iqué bueno!, esta es la culminación de un proceso; pero habrán algunos proyectos que no se construyan, pero son igualmente válidos en ese proceso de ejercer nuestra profesión.

I VS: Yo tengo discrepancias, porque si la cosa es así estaría devolviendo mi título... porque yo te puedo decir que no tengo metros cuadrados de proyectación, pero he participado desde la contraparte en grandes proyectos...

I PM: Proyectos en el entendido como todo lo necesario para materializar una obra...

I VS: Exactamente, pero lo que me complica a mí es que hay veces que se entiende el proyecto como la obra..

PAUSA (Antes de continuar la conversación, los invitados aclaran sus puntos de vista off the record ${ }^{18}$ ).

\section{Sobresaturación de arquitectos y autorгegulación}

/ PM: Mi visión es que hoy día el acceso al trabajo, por parte de [las] oficinas establecidas se ha democratizado [mucho], porque es distinto al del arquitecto que trabaja en su casa o con un amigo, que recién está partiendo. Para [las] oficinas establecidas, hoy en día ya no es como era hace veinte o quince años que el mandante tenía contigo una fidelidad a toda prueba. Hoy en el ámbito en que me manejo yo, a los arquitectos que llevan un proyecto a una determinada inmobiliaria, se los dan, aunque no tenga demasiada experiencia: ¿por qué?, porque a un profesional joven con cinco años de experiencia se asocia otro con más experiencia y ya.

Entonces se ha democratizado. A nosotros que somos una oficina grande para el medio chileno, nos cuesta mucho. Hace veinticinco años había cinco oficinas en Chile que tenían todo el trabajo y se llevaban el ochenta y cinco por ciento del trabajo. Yo estoy metido en la Asociación Chilena de Arquitectos ${ }^{19} \mathrm{y}$ hemos hecho un estudio de cómo se distribuye el trabajo de las oficinas establecidas (en Chile) y no es que un par de oficinas se [lleve] todo el trabajo.

IVS: Bueno, me alegro mucho de escucharlo, en todo caso, yo creo que si esas oficinas se llevan el trabajo es porque se han afiatado, es porque han logrado un aprendizaje que las hace muy competitivas, eso y nada más.

Lo que si me duele constatar que hay una sobreoferta de arquitectos en relación a los requerimientos de este país, yo encuentro que eso tiene que regularse.

/ MP: Y hay que ver el tipo de formación que tienen.

I VS: Bueno sin pronunciarme respecto del tipo de formación (porque yo no soy quién para emitir juicios al respecto), me parece dramático, porque son jóvenes que estudian con mucho esfuerzo y resulta que: ¿para qué?, porque sobre todo si hubieran estudiado [otra] carrera [sobresaturada], [en la que] fuese más fácil una reinterpretación, pero un arquitecto: ¿cómo se reconvierte? El tema de cómo un arquitecto se reconvierte es más complicado [que el de] un profesor [que] se reconvierte, o un historiador, hay muchas maneras de reconvertirse. Si estás en otro ámbito -humanista o científico- incluso tú tienes más versatilidad para reconvertirte, pero en el ámbito de la arquitectura dime ¿cómo te reconviertes?

/ MP: Bueno pero en esa encuesta que salió publicada hace dos años en relación a los salarios a que aspiraban los distintos profesionales los primeros dos o tres años de título, arquitectura aparecía con ingresos bastante bajos y resulta que ese año la demanda bajó y significó que bajaran las postulaciones a arquitectura, porque [la gente] mira cuanto va a ganar y después ve si postula a la carrera. Ingeniería en minas subió su puntaje en forma considerable ese año porque resulta que eran los que mejor ganaban recién egresados.

/ PM: Pero eso al final es un proceso de autorregulación.

\footnotetext{
Sin registro grabado.

9 AOA. En la actualidad, Patricio Morelli es Past President de esta organización.
} 
I vs: Exacto, si va a ser así, que algunas carreras cierren no más. Que algunas facultades digan ¿sabes? esto no me está dando.

/ MP: Hoy debieran acreditarse las carreras y dictarlas sólo aquellas que pueden hacerlo como es debido. Porque hoy en día las universidades privadas se nutren de los académicos de las universidades tradicionales. No tienen bibliotecas, no desarrollan investigación, no son complejas: simplemente dictan docencia, y en los horarios más insólitos. Los alumnos tienen clases de ocho a nueve y media, y de seis a diez de la noche porque es el horario en que el profesor pudo ir a hacer clases.

I VS: En todo caso [viéndolo desde afuera], yo diría que hay algunas universidades privadas, que se han posicionado bien [pero] hay [otras en] que tú miras los currículum y dices para afuera, no miras más.

/ MP: Eso se llama sesgo, porque yo creo que las universidades privadas no están cerca de las tradicionales en términos de la complejidad que pueden entregar, sin embargo creo que hay buenos profesionales en todas partes, porque cuando tú entrevistas gente de la Chile o de la Católica, de tal o cual universidad privada, y con nombre y apellido: de la Mayor, la Finis Terrae, la del Desarrollo, etc... te das cuenta que los postulantes son buenísimos y después les haces un examen, los aceptas en el magíster y obtienen excelentes notas y los que llegaron al final como producto son semejantes.

Algunos dicen que los que llegan a posgrado son los mejores o son semejantes, por eso puede ser que no hay diferencias. Pero si uno analiza lo que entregan las universidades en investigación, en docencia: ¿qué pasa con el conocimiento?, ¿quiénes están llevando conocimiento a las privadas?, la gente que fue formada en las tradicionales.

/ PM: Bueno finalmente las universidades privadas -este es un tema de plazos y de desarrollo- van a tener investigación.

IVS: Claro, porque además tienen los recursos.

/ MP: Claro si la Andrés Bello y la Mayor tienen la misma cantidad de posgrados que nosotros, finalmente en la suma y resta es positivo.
/ PM: Claro.

IVS: Si lo que no es positivo es tener tal cantidad de facultades de arquitectura por todos lados, porque no se requieren tantos arquitectos.

/ PM: Eso se va a regular, van a desaparecer.

\section{Algunas conclusiones} final.

I LP: Vamos a hacer una pequeña ronda

/ PM: Para terminar, yo sigo siendo optimista; todo esto tiene que ver con el desarrollo del país. Creo que estamos en lo correcto, si las vicisitudes de la Universidad de Chile [como] conciencia pública y el problema financiero, lo vamos a solucionar... en diez o quince años más, porque vamos a seguir compitiendo con las privadas que tienen todos los recursos.

Finalmente en el tema de pregrado, creo en la formación más generalista que específica, creo en la importancia de los posgrados cada vez más creciente, pero también estoy de acuerdo con Verónica en que el tema de los posgrados tiene que ver con requerimientos profesionales y no creo en esta gente que a los 25/26 años ingresa al posgrado y que después de recibirse hacen el siguiente posgrado y el siguiente... y creen que tienen una base de oficio que les va a permitir tener grandes ingresos, y eso no es así, porque los buenos ingresos se ganan en el tiempo, con el expertise, esforzándose todos los días. En ese sentido también creo que se va a regular porque la gente no es tonta, pero tiene que pasar tiempo.

I MP: A ver, yo quiero volver al tema Grandes Operadores - Pequeños Negocios, y en ese sentido creo que lo importante, como una mirada al arquitecto que egresa de nuestra Facultad y en general de nuestra profesión, es que hay espacio para todos. Son todos diferentes caminos con objetivos semejantes, creo que hoy es cuando existen mejores posibilidades para los arquitectos en distintos escenarios, independientemente de que se hayan cerrado espacios tradicionales como el sector público, que es una cuestión lógica ya que es cada vez más pequeño.

En el espacio privado que es a lo que la gente aspira, creo que también hay mucho espacio, y creo que hay espacio para grandes oportunidades en lo que las grandes oficinas no están haciendo y que los chicos deben mirar. Hay espacio para los arquitectos nuevos que quieren emprender un camino solos y creo que esas oportunidades están en el medio.

Creo que la relación con las inmobiliarias es muy atractiva, creo que el manejo de productos nuevos, entender lo que está pasando, estar más alerta de las necesidades de la gente, hace que los nuevos arquitectos tengan una mayor posibilidad de interactuar ya no con el cliente, sino con el potencial cliente que se llama demanda y que está en la masa. Creo que ese es un espacio interesante y debemos enseñarles eso a nuestros alumnos para que no se quejen por falta de trabajo. Creo que hay cuestiones que hay que poner en valor, como son las gestiones públicas en los diferentes ambientes. Creo que nosotros como universidad tenemos un compromiso en ese sentido, en transmitirle a la gente que no todos van a ser arquitectos para construir los grandes edificios, sino que la arquitectura es tan noble y tan útil independiente del producto o del lado de la mesa en que se esté El mensaje debe ser optimista, porque cada vez hay más espacio, lo que pasa es que hay que descubrirlo, no es el tradicional, no es lo que fue nuestro profesor, es otro, y yo creo que esa es la motivación, lo que decía en un principio en relación a la flexibilidad, de ser lo suficientemente amplios en la transmisión del conocimiento y lo suficientemente flexibles, para darse cuenta de que hay cosas que no son tan necesarias, hay que entregar nuevas miradas.

/ VS: Yo quisiera poner énfasis en tres cosas no más, primero, creo que este es un país que está teniendo oportunidades muy grandes, es un país que ha cambiado mucho, que tiene un potencial de desarrollo mucho más accesible hoy en día. Pero en ese contexto los arquitectos también tienen que repensarse. La proactividad de un profesional es central, la versatilidad para encontrar espacios, tener abiertas las redes es determinante. En eso las universidades son responsables respecto de las herramientas que les entregan, no sólo de la formación específica. La gente que hace grandes logros es la gente que ha tenido habilidades en las áreas de la creatividad, el liderazgo, el emprendimiento.

Luego lo otro, más político en términos de hacerse cargo de que la arquitectura no es un artefacto, una entelequia bonita, sino que es una respuesta a necesidades humanas y sociales concretas y siento a veces que hay distancias. Se requiere hacerse cargo del país 
Revista de Arquitectura agradece la cordial acogida de Claudio Soto Barría, quien tuvo la gentileza de facilitar la realización del presente Foro en la Cava del Bicentenario de su tradicional establecimiento la "Confitería Torres".

en que vivimos y que el profesional contribuya desde donde quiera que esté, desde una visión política, cristiana, lo que sea. Nuestra profesión debiera contribuir a la sociedad, es construir sociedad.

El último punto es que el tema no es un encargo específico y acotado, sino que es mucho más integral, la disposición a trabajar en equipo, a trabajar desde distintas ópticas, adecuarse a los tiempos me parece crucial. Hablamos [que] la distancia del Estado y el sector privado, incluso del sector académico es otra, ahora el Estado no construye grandes cosas desde sí mismo. Antes el arquitecto estaba sentado en la oficina del Estado haciendo grandes obras, esa cuestión se da cada vez menos y nos interesa abrir el espacio para que la gente sea (todos, los profesionales, todos los ámbitos) la que resuelva estos aspectos, y nosotros ser habilitadoresarticuladores de este proceso.
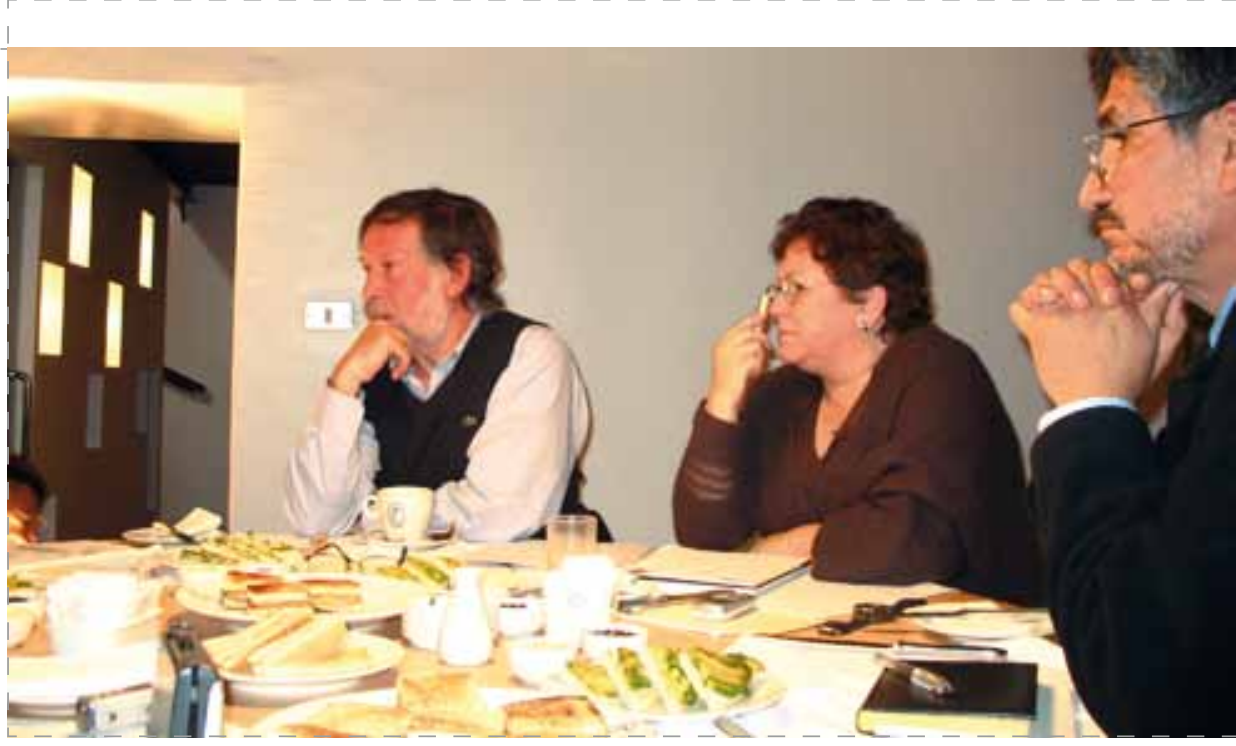

Yo también tengo una visión optimista. Ahora también tengo preocupación por la sobresaturación de arquitectos, porque lo veo de forma diaria, ahora supongo que esto ha pasado en otras carreras y se resuelve, pero ia qué costo? Ver que gente que ha trabajado con tanta dedicación, entusiasmo, con vocación incluso, se queda fuera, es duro.

/ EC: Muy breve, simplemente recordar el nombre de este foro. Es una provocación para nosotros en el sentido de reafirmar la necesidad desde la academia de, fundamentalmente, reflexionar sobre estos nuevos escenarios que se nos vienen encima, pero yo insisto que ese poder asumir la complejidad sobre la realidad, tiene que traducirse en propuestas concretas: una concepción de taller manteniendo los elementos esenciales que le dan sentido a la formación del arquitecto, construcción de un discurso propio, desarrollo de nuevas competencias, capacidad de ser más sensible a esa realidad desde el punto de vista profesional, convicción de que el germen de esa posibilidad de ir construyendo todo aquello tiene que asumirlo la universidad.

Es [esta última], la plataforma central desde la cual se aportan luces para que los otros agentes sociales vayan recogiendo e incorporándolas desde los roles que cada uno asume: oficinas profesionales, ejercicio particular, Estado, municipios, sociedad en general. Sigo pensando que es desde la universidad que se debiera consolidar esta posibilidad de entender mejor la realidad, tomar la distancia e iniciar la construcción de una propuesta que nos permita insertarnos mejor en el mundo actual y proyectarnos a futuro.

/ LP: Finalmente quiero darles las gracias en nombre de Revista De Arquitectura porque ya estamos acercándonos a la hora.

Nuevamente, muchas gracias. 